\title{
Simple Test for Ingested Iron in Hospital and Domiciliary Practice
}

\author{
A. M. AFIFI, M.B., M.R.C.P.ED. ; G. S. BANWELL, $\dagger$ M.A., F.R.C.S.ED., M.R.C.o.G. \\ R. J. BENNISON, $\ddagger$ M.B., B.CHIR, D.OBST.R.C.o.G.; K. BOOTHBY, $\ddagger$ M.B., CH.B. \\ P. D. GRIFFITHS,§ M.D., B.SC., M.C.PATH.; R. G. HUNTSMAN,\| M.D., M.R.C.P., M.C.PATH. \\ G. C. JENKINS, I M.B., PH.D., M.C.PATH. ; R. G. LEWIN SMITH, M.A., B.M., B.CH. \\ J. MCINTOSH, $\ddagger$ M.B., B.S., D.OBST.R.C.O.G., D.C.H. ; A. QAYUM,* M.D. \\ I. ROSS RUSSELL, $\ddagger$ M.B., B.CHIR., D.OBST.R.C.o.G.; J. N. WHITTAKER, $\ddagger$ M.B., CH.B.
}

Brit. med. F., 1966, 1, 1021-1022

Widespread use of iron preparations has resulted from recognition of the greater metabolic requirement of iron in pregnancy. The side-effects ascribed to these drugs by patients have made many practitioners doubt that all their patients carry out the prescribed treatment. Indeed, one practitioner has observed that when the antenatal patients were given an iron preparation and told that these tablets were "vitamins" they would remind him that they had finished the supply. This was a rare occurrence before the subterfuge was practised.

Failure to take the tablets results in a toxic substance lingering in a household often containing children. Also patients may be labelled improperly as cases of "iron-resistant pregnancy anaemia," with consequent resort to parenteral iron or blood transfusion.

The lack of a simple test for checking on iron intake has hampered objective assessment of iron deficiency in a pregnant population to whom iron has been dispensed freely. To meet this need a rapid test, which requires no elaborate apparatus, has been devised. The results of its use in hospital and general practice form the substance of this communication.

\section{Procedure}

Subjects.-Random antenatal patients to whom oral iron preparations had been dispensed were requested to provide a specimen of faeces.

Technique.-A portion of the faecal specimen is emulsified in $2 \mathrm{~N}$ hydrochloric acid by means of two orange sticks to a creamy consistency. By means of the sticks a drop of the emulsion is transferred to the centre of a Whatman No. 1 filter paper. The consistency must be thick enough to avoid falsenegative results but thin enough for a clear halo of fluid to emerge at one to two minutes (see Fig.). One drop of aqueous $0.25 \%$ potassium ferricyanide is then placed alongside so that the two fluids meet at their periphery. A positive result is indicated by the immediate appearance of a blue crescent (ferrous ferricyanide, or Turnbull's blue). Potassium ferrocyanide cannot be used, as a blue crescent (Prussian blue) is obtained on specimens from many subjects not receiving iron therapy. If the patient is taking $40 \mathrm{mg}$. of iron-for example, one tablet of ferrous gluconate-a day a positive result will almost always be obtained. Ferrous sulphate, which contains $60 \mathrm{mg}$. of elemental iron, leads to a stronger colour.

The presence of blood does not invalidate the test. Six stools with positive occult blood tests obtained from patients

\footnotetext{
* Late Senior House Oficer in Pathology, Lambeth Hospital, London + Consultant Obstetrician, Harlow Group of Hospitals. † Consultant Obstetrician

Consultant Pathologist, Harlow Group of Hospitals.

II Consultant Haematologist, Lambeth and St. Thomas's Hospitals, London.

I Consultant Haematologist, London Hospital.
}

$\checkmark$

not receiving iron, and stools from one of us who swallowed $20 \mathrm{ml}$. of blood a day for five days, were negative to the ferricyanide test. Storing the faeces for several weeks did not alter their reaction to this test.

\section{Results}

The reliability of the test was assessed initially on more than 200 specimens from healthy male subjects on a normal diet, half the subjects being given one tablet of ferrous sulphate

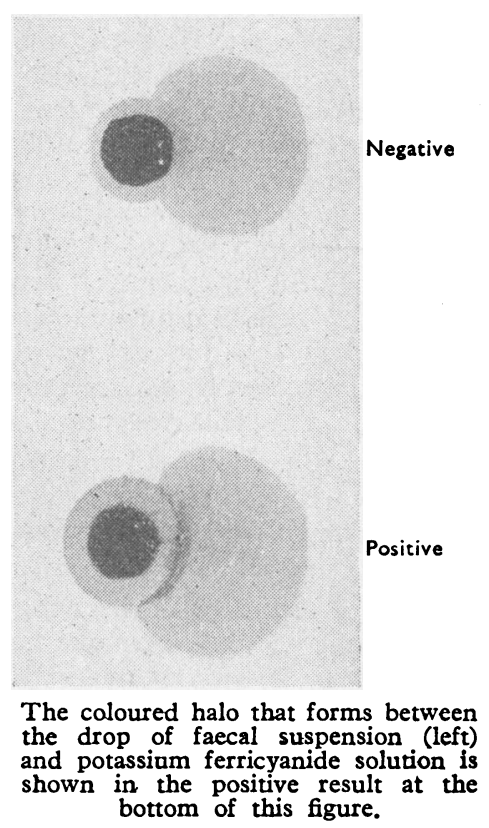

or gluconate a day. A negative result was obtained in all the controls, and all but two specimens from the subjects receiving iron produced stools which gave a clear positive result. The larger dose of iron usually employed therapeutically might be expected invariably to yield a positive test on the patient's stool.

A further trial was carried out with eight normal pregnant women, who were asked to collect three stool samples on different days before they were given iron, and then to repeat these collections while receiving one tablet of either ferrous sulphate or ferrous gluconate a day. All control specimens were negative. Only one of the eight patients produced specimens which gave a negative result during the test period, and this unmarried mother produced six further specimens, which were all positive, when her iron intake was supervised by the matron of the home in which she was staying. 
The results obtained when the teit was used in practice for 338 patients attending three hospital antenatal clinics, and 145 patients of six general practitioners, are shown in the Table. The figures suggest that in both groups $28 \%$ of the patients had been taking less than one iron tablet daily at the time they were tested.

Results of Ferricyanide Test for Iron on the Stools of Pregnant Patients

\begin{tabular}{|c|c|c|c|c|c|c|c|c|c|c|c|}
\hline \multirow{2}{*}{ Test } & \multicolumn{4}{|c|}{ Hospital } & \multicolumn{7}{|c|}{ General Practitioner } \\
\hline & 1 & 2 & 3 & Total & 1 & 2 & 3 & 4 & 5 & 6 & Total \\
\hline $\begin{array}{l}\text { Positive } \\
\text { Negative }\end{array}$ & $\begin{array}{l}79 \\
40\end{array}$ & $\begin{array}{l}84 \\
25\end{array}$ & $\begin{array}{l}80 \\
30\end{array}$ & $\begin{array}{r}243 \\
95\end{array}$ & $\begin{array}{l}9 \\
1\end{array}$ & $\begin{array}{r}10 \\
5\end{array}$ & $\begin{array}{r}22 \\
8\end{array}$ & $\begin{array}{l}41 \\
18\end{array}$ & $\begin{array}{r}15 \\
7\end{array}$ & $\begin{array}{l}8 \\
1\end{array}$ & $\begin{array}{r}105 \\
40\end{array}$ \\
\hline
\end{tabular}

\section{Discussion}

If the test is a reliable index of therapeutic iron intake a remarkably high proportion of the patients apparently fail to take the iron prescribed for them. This represents, in this country, a wastage of some 5 tons $(5,080 \mathrm{~kg}$.) of elemental iron annually, the amount of iron in about eight small motor-cars.

Hitherto, objective assessment of this problem has been difficult. Methods for determination of faecal iron are timeconsuming and complex (Ybema, Leijnse, and Wiltink, 1965), and Bothwell and Finch (1962) have questioned their reliability as an index of iron absorption. The radioactive-iron techniques of Israëls and Cook (1965) could not be used in pregnancy. Direct questioning and/or checking the number of tablets remaining with prescriptions issued has also been employed. The former method must rely to some extent on the patient's honesty, and the latter on her intelligence. Direct questioning methods led both Smith (1961) in general practice and Vanier (1963) in a teaching hospital to conclude that about $70 \%$ of prescribed iron was taken. Benstead and Theobald (1952) concluded that 30 to $40 \%$ of antenatal patients would not take routinely prescribed ferrous sulphate tablets; Haler (1952) observed that "quite $25 \%$ " of out-patients would discontinue oral iron therapy because of intestinal intolerance. The methods by which these figures were obtained was not indicated.

By counting tablets prescribed, Chanarin, Rothman, and Berry (1965) concluded that on the average two out of three tablets a day were taken. Thus the results obtained in the present survey are in agreement with previous assessments.

In hospital two 21 of the 25 patients giving negative results were interviewed by one of us. The question posed, "You seem to be doing very well without taking your iron tablets, but why aren't you ?" was chosen as a form most likely to encourage a truthful answer. All 21 admitted they had not been taking their tablets, the most common excuse being nausea and constipation.

In hospital three 21 of the 30 patients with a negative test admitted that they had not taken their tablets, but the remaining nine claimed they had. Questioning was carried out by various members of the clinic staff, the form of question being left to the individual. Had a direct question (accusation ?) been employed, possibly the automatic reaction of many would be to deny the charge, perhaps explaining the difference between the results from the two hospitals. Only a few of the patients with a negative test in the third hospital were questioned, and all agreed they were not at that time taking iron. Almost $50 \%$ of the patients in this hospital appeared not to be taking their tablets, and, unlike those at the other two hospitals, a large number were immigrants.

With experience a reasonably accurate assessment of whether or not a patient was taking iron can be made by inspection of the colour of the stool, which changes from the normal brown to a grey-black. It is surprising that in so-called ironresistant anaemias inspection has not been resorted to more often. The consistency of the stool gave no guide to whether or not the patient was taking iron.

In our hands the test has proved a reliable index of whether or not a patient is in fact taking oral iron. In view of its simplicity, and the advantage that the result can be obtained while the patient is still in attendance, it is suggested that it might be a useful screening procedure in the investigation of the so-called iron-resistant pregnancy anaemia (and possibly of other non-responsive iron-deficiency anaemias), as a negative result raises doubt whether the patient was carrying out instructions by taking her iron. A discrepancy between the result of the test and the patient's story might be regarded as an indication for attempting one of the more complex tests of iron intake, but in our experience recourse to this action is not likely to be necessary.

\section{Summary}

A simple screening test to check ingestion of prescribed oral iron is presented. The use of this test on 483 pregnant patients in hospital and domiciliary practice suggests that $28 \%$ were failing to carry out their treatment at the time they were tested. If there is a discrepancy between the test result and the patient's story resort to a more complex test of iron intake might be considered before labelling the patient "iron-resistant."

It gives us pleasure to record our appreciation of the ready co-operation of the medical and nursing staff of the antenatal clinics of Princess Alexandra (Harlow), Lambeth, and the North Middlesex Hospitals.

\section{REFERENCES}

Benstead, N., and Theobald, G. W. (1952). Brit. med. f., 1, 407. Bothwell, T.' H., and Finch, C. A. (1962). Iron Metabolism. Churchill,

London.
Chanarin, I., Rothman, D., and Berry, V. (1965). Brit. med. F., 1, 480. Chanarin, I, Rothman, D., and
Haler, D. (1952). Ibid., 2, 1241 .

Israëls, M. C. G., and Cook, T. A. (1965). Lancet, 2, 654.

Smith, R. M. E. (1961). Personal communication

Vanier, T. M. (1963). Personal communication.

Ybema, H. J., Leijnse, B., and Wiltink, W. F. (1965). Clin. chim. Acta, 11, 178 . 